\title{
«Волнуемая стыдом и страхом»: инфантицид в Таврической губернии в русле истории повседневности Таврической губернии середины XIX - начала XX вв.
}

\author{
Масленникова В.А. \\ Таврическая академия Крымского федерального университета имени Вернадского, \\ Россия, 295007, Симферополь, просп. Вернадского, 20 \\ E-mail: Ms.Valeris@bk.ru
}

\begin{abstract}
Аннотация. Как общество воспринимало женщину, решившуюся на лишение жизни собственного, но незаконнорожденного ребенка - это важный вопрос, который обнажает негативные стороны патриархального строя, который все еще довлел над обществом середины XIX - начала XX вв. В Уложении о наказаниях уголовных и исправительных в ст. 1451 и ст. 1460 прямо указывалось, что стоит принимать во внимание «особое несчастное положение преступницы, волнуемой чувствами стыда, страха, и ослабленной от страданий физических», таким образом, снимая с женщины образ жестокой детоубийцы и давая ей шанс на помилование. В статье анализируются источники, позволяющие оценить отношение общества к тем девушкам, кто забеременел вне брака. Освещается социальное положение будущих детоубийц. Автор уделяет особое внимание реальным количественным показателям мертворожденных детей, соотносит медицинские данные со свидетельствами детоубийц. В статье рассмотрены основные способы инфантицида. В статье дана оценка применяемого наказания к женщинам, лишивших жизни своих детей.
\end{abstract}

Ключевые слова: женщины, преступность, инфантицид, детоубийство, убийство, Таврическая губерния.

Для цитирования: Масленникова В.А. 2021. «Волнуемая стыдом и страхом»: Инфантицид в Таврической губернии в русле истории повседневности Таврической губернии середины XIX - начала XX вв. Via in tempore. История. Политология, 48 (2): 415-423. DOI: $10.52575 / 2687-0967-2021-48-2-415-423$.

\section{«Agitated by shame and fear»: infanticide in the Tauride province in the course of the history of everyday life in the Tauride province of the mid-XIX - early XX centuries}

\author{
Valeria A. Maslennikova \\ Taurida Academy of the Vernadsky Crimean Federal University, \\ 20 Ave. Vernadsky, Simferopol, 295007, Russia \\ E-mail: Ms.Valeris@bk.ru
}

\begin{abstract}
How society perceived a woman who decided to take the life of her own illegitimate child is an important question that exposes the negative aspects of the patriarchal system that still dominated society in the mid-XIX - early XX centuries. In the Code on Criminal and Correctional Punishments in Articles 1451 and 1460, it was explicitly stated that it was worth taking into account «the special unfortunate situation of the criminal, agitated by feelings of shame, fear, and weakened by physical suffering», thus removing the image of a cruel child killer from the woman and giving her a chance for pardon. The article analyzes the sources that allow us to assess the attitude of society to those girls who became pregnant out of wedlock. The social situation of future child murderers is highlighted. The author pays special attention to the actual quantitative indicators of stillborn children, correlates medical data with evidence of infanticide. The article describes the main methods of infanticide. The article assesses the punishment applied to women who have taken the life of their children.
\end{abstract}


Keywords: women, crime, infanticide, infanticide, murder, Tauride province.

For citation: Maslennikova V.A. 2021. "Agitated by shame and fear»: infanticide in the Tauride province in the course of the history of everyday life in the Tauride province of the mid-XIX - early XX centuries. Via in tempore. History and political science, 48 (2): 415-423 (in Russian). DOI: $10.52575 / 2687-0967-2021-48-2-415-423$.

\section{Введение}

Актуальность злободневной проблемы детоубийства не угаснет до тех пор, пока с повестки дня не сойдут такие темы, как преступность, бедность и недоступность первоклассного медицинского обслуживания. На данный момент можно встретить новости с подобными заголовками: «нет тела, нет дела», где рассказывают о женщинах, избежавших наказания за детоубийство в XXI веке. Приоткрывая завесу прошлого, мы сможем оценить отношение общества к данному преступному деянию в пореформенный период.

K началу XIX в. церковь прочно утвердила святость брачного союза с помощью общественного мнения и религии. Преуспела она в этом настолько, что вся тяжесть стыда от внебрачного рождения падала исключительно на женщину - существо более слабое, «придавленное» патриархальным строем. Как известно, общественное мнение во все времена - великая сила. Именно поэтому желание скрыться от стыда и бесчестья толкало женщину на преднамеренное убийство своего родного, но незаконнорожденного ребенка.

Цель данного исследования состоит в реконструкции социального самочувствия женщин, проживавших на территории Таврической губернии и совершивших преступления по ст. 1451 (лишение жизни незаконнорожденного ребенка «по мотивам стыда и страха») либо по ст. 1460 (оставление в опасности, с летальным исходом) Уложения о наказании Российской империи [Таганцев, 1871, с. 180, 270]. В связи с заданной целью проанализирована историческая литература и источники, касающиеся темы инфантицида. Дана оценка общественного отношения к самому преступному деянию и женщине, совершившей его. Приведены примеры, демонстрирующие реальное социальное самочувствие девушек, решившихся на преступление на территории Таврической губернии. Раскрыты основные причины незапланированных беременностей девушек. Выделен процент действительно мертворожденных детей в изучаемый период времени. В исследовании рассматриваются основные способы убийства новорожденных детей, приведены примеры из реальной жизни жительниц уездов и городов Таврической губернии. Подведен итог о наказании девушек, совершивших инфантицид.

\section{Объекты и методы исследования}

Методологической основной исследования выступил анализ преступной деятельности, попадавшей под определение детоубийства. Анализ позволил внедрить в историкосистемный метод синтезированную информацию и предоставить полноценную картину происходящего. Метод индукции позволил провести аналогии и предоставить целостную картину происходящего по заданной теме.

Сама тема детоубийства интересовала ученых давно. Уже в начале 60-хх гг. ХІХ вв. ученые подчеркивали решающий фактор общественного мнения о женщине, родившей вне брака, в преступлениях о детоубийствах [Несколько случаев детоубийства, 1862, с. 187]. Ю. Охорошвич призывал общественность и суд «оставить призывы жестко расправляться с детоубийцами», указывая на доминирование базовых причин, которые в совокупности подводили женщину к страшному выбору [Любовь, преступление, 1876, с. 116].

На 12-м Пироговском съезде проблеме инфантицида посвятили значительное количество докладов. Основные выводы, к которым пришли исследователи, заключались в том, что «история демонстрировала нам: аборт - предохранительный клапан от детоубийства» [Общество русских врачей, 1913, с. 86]. Не обошли вниманием и негативную тен- 
денцию, состоящую в том, что бич дореволюционного общества - «нежелание иметь детей», и связано это было по большей мере с социально-экономическими причинами [Общество русских врачей, 1913, с. 85].

М.Н. Гернет в своем социально-юридическом исследовании детоубийств рассмотрел процесс становления наказания за данные злодеяния в ряде европейских стран и на территории Российской империи. Ученый привел статистику за 1897-1906 гг. по ряду преступных деяний, совершенных женщинами, и пришел к выводу, что детоубийство и оставление в опасности - специфические женские преступления. Так же в составленной М.Н. Гернетом таблице видно, что большую часть женщин, судившихся за инфантицид, оправдали [Гернет, 1911, с. 66] Весомый вклад в изучение «сугубо женского» преступления внес исследователь С.С. Шашков [Шашков, 1898]. Ряд ученых рассматривал данную тему сквозь призму территориальных особенностей [Лиденберг, 1910; Глебовский, 1912]. Однако в большинстве случаев они склонялись к общепризнанному факту - социальноэкономические условие довлели над девушками, решавшимся на данное злодеяние.

Советский исследователь Л.М. Василевский находил «сочувствующие нотки» и в законодательных актах дореволюционной России, касающихся инфантицида [Василевский, 1927, с. 20]. Исследователь советского периода, проанализировав детоубийства в дореволюционной России и сравнив полученные данные с другими европейскими странами, пришел к выводу, что на территории России количество детоубийств в сельской местности превосходило число данного преступления в городах практически вдвое [Змиев, 1927, с. 90]. Однако это обстоятельство ученый связал с тем, что в сельской местности было сложнее скрыть факт беременности, а также избавиться от трупа ребенка.

Современные авторы рассматривают различные аспекты детоубийства, среди исследований числятся и попытки классифицировать инфантицид [Шевченко, 2018] и реконструировать историческое становление наказаний за данное злодеяние [Бабичев, 2015]. Так же есть исследования по территориальному отношению, к примеру, губерний Центрального Черноземья [Жеребчиков, 2017]. Так же важно уделить внимание исследованиям об абортах и абортивной деятельности среди женщин Российской империи [Мицюк, 2019; Юкина, 2019].

Источниковую базу данного исследования дополняют документы Государственного архива Республики Крым, а также периодические издания Таврической губернии.

\section{Результаты и их обсуждение}

Закон, вооруженный уголовным наказанием, вступал в неравную борьбу с общественным осуждением. Желание сохранить за внешним образом свою честь толкало женщину на преступление. Шанс скрыть данное злодеяние был довольно велик. К тому же довольно часто сомнению подвергалась сама причина смерти: был ли ребенок мертворожденный или убиенный [Орлов, 1868, с. 142]. Положение изменялось с конца 90-х гг. XIX в., когда в делах о детоубийствах и об обнаружении мертвых тел младенцев начали фигурировать результаты вскрытий. Судебно-медицинская экспертиза достоверно могла указать на такие вещи, как: был ли ребенок мертворожденным; был ли он жизнеспособен; выявить причину смерти тоже становилось более возможным, чем это было ранее. Следовательно, женщину неминуемо ожидало наказание и обличение.

Весьма парадоксально, однако, в данном случае общественное мнение проявляло сочувствие преступнице. Например, к концу XIX в. наметилась четкая тенденция, проявляющаяся в смягчении наказания за подобные преступления не законом, а самими судьями. Возможно, таким образом проявлялся гуманизм со стороны «власть имущих». Законники, видимо, учитывали, что сами условия жизни толкали девушек на такие преступления.

Наука к началу XX в. проявляет все больший интерес к эмоциональной стороне женщин, влияния на них социума. Женщина представала пред современниками как легко ранимое существо, подпорченное условиями жизни и нещадного эксплуататорского труда. 
На рубеже XIX-XX вв., считалось, что в основу преступления были положены два фактора: психофизический и экономическо-бытовой. В большинстве случаев присутствовал явный симбиоз двух причин, а связующим звеном служил «стыд и страх», имеющий под собой ложное понятие о женской чести. Стоило только «оступиться» неопытной девушке, и целая масса оскорблений и издевательств падало на ее голову извне, ставя перед ней вопрос о спокойном существовании и заработке. Причем сохранить жизнь малютке не было средств. К примеру, мещанка А.А. Миренкова, бросившая своего новорожденного в ретирадное место и предпринявшая попытки убить ребенка, кинув вслед три больших камня, пыталась оправдать себя тем, что «на прежнюю службу к доктору Музе с ребенком брать не хотели, а отдать в приют ребенка у нее не было средств» ${ }^{14}$.

Вина за преступление всегда возлагалась на девушек, не на мужчину, навлекшего беду, и не на общество, в котором она росла. На жизнь незамужней беременной женщины ставили клеймо общего презрения, вводя в ее жизнь трагизм личного существования. И если в деревнях иногда доходило до крайностей, полного вычеркивания из социальной жизни, то в городах к таким роженицам относились более снисходительно, особенно в среде фабричных рабочих и интеллигенции. Ведь за отсутствием других интересов чья-либо беременность становилась чем-то сенсационным: «такая-то «забрюхатила», «понесла», «запусатила» [Глебовский, 1904, с. 46-47]. Иногда особо сообразительные девушки выходили из незавидного положения таким способом - заявляли о своем изнасиловании, подавали жалобы, в некоторых случаях требовали векселя на уплату за содержание ребенка ${ }^{15}$.

Однако большинство детоубийц Таврической губернии были не жертвами насилия, а «жертвами внезапно вспыхнувшей страсти». Об этом может свидетельствовать юность девушек. В основном возрастные рамки варьировались от 16 до 23 лет. Конечно, существовали и отдельные случаи, в которых возраст обвиняемых доходил и до 75 лет. Однако процент таких дел слишком мал, чтобы пытаться вычленить некую закономерность среди лиц старшего возраста. Можно предположить, что дамы, будучи в более солидном возрасте и имея за плечами некий жизненный опыт, более тщательно скрывали свое положение и следующие за тем последствия.

К концу XIX в. вопрос детоубийства начал вызывать неподдельный интерес среди народных масс. Периодическим изданиям была присуща эмоциональная окраска происходящего, иногда текст добротно разбавляли комментариями авторов. Зачастую, описывая подобные случаи, авторы акцентировали внимание, что «такая мать не безнравственная женщина, а глубоко несчастная» [Салгир, 1898, № 131, 26 октября, с. 1]. Женщин, отправляющих своих малюток в выгребные ямы, порицали, осуждали, пытаясь с помощью слов предотвратить будущие преступления такого рода [Салгир, 1898, № 159, 27 ноября, с. 3]. Даже в таких заметках о столь безнравственных поступках можно уловить нотки сострадания. Таким образом, сквозь строки периодики мелькал косвенный анализ социальнополитических проблем в обществе, который цензура вряд ли бы одобрила в открытом виде.

Профессионально ориентированную публику интересовали способы исполнения преступления. Такая информация помещалась в учебниках судебной медицины. Учебные пособия С.А. Громова, которые пользовались популярностью около полувека, к середине 80-х гг. ХІХ в. морально устарели [Громов, 1832, 554 с.; Громов, 1838, 576 с.]. В 1887 г. профессором судебной медицины И.М. Сорокиным был переведен «Учебник судебной медицины» Э.Р. Гофмана. Именно этот исследователь разделил детоубийства по определенным способам. Исследователем было отмечено, что из всех активных способов убийства новорожденных чаще всего встречались повреждения черепа тупыми предметами, причем чаще всего удар приходился именно в голову. Убийства новорожденных ударами, толчками и вообще насилием, направленным на другие части тела, встречались лишь в

\footnotetext{
${ }^{14}$ ГАРК Ф. 376. Оп. 6. Д. 392. Л. 3. О мещанке Анне Алексеевной Миренковой, обв. в покушении на убийство ребенка. Начало 10 декабря 1904 г.

${ }^{15}$ ГАРК Ф. 118. Оп. 1. Д. 3342. Л. 2-3. Изнасилование.
} 
виде исключений, и все равно такие травмы были непосредственно сопряжены с травмой головы [Гофман, 1887, с. 609]. Задушение встречалось так же часто. Автором отмечалось, что внешние признаки, если удушение происходило с долей «утонченности» (например, мягким предметом - платком), плохо поддавались опознанию [Гофман, 1887, с. 613]. Однако, учитывая, что такой вид убийства чаще встречался в сельской местности, к которой слово «утонченность» и «изящество» редко применимо, душили просто руками, толстыми и грубыми веревками, что оставляло явные следы. Прочие виды насильственной смерти новорожденных, за исключением смерти от утопления, встречались крайне редко [Гофман, 1887, с. 614]. Убийство малышей режущими предметами или колющими орудиями встречались еще реже.

Удивительно, но практически все обвиняемые женщины твердили, что их ребенок был мертворожденный, и они, «волнуемые стыдом и страхом», просто предавали «дитятко земле». По данным Симферопольского окружного суда, абсолютно все женщины были безграмотны. Вполне возможно, из-за низкого распространения медицинских знаний среди населения женщины не понимали, что такое судебная медицина и как с ее помощью опровергалась их ложь. Ведь на самом деле лишь $12 \%$ детей действительно были мертворожденными. Процент деток, оставленных без помощи или скончавшихся от недостаточного ухода, включая недоношенных и нежизнеспособных, превышал $20 \%$ (наиболее точные данные установить не представляется возможным, ведь эти данные основаны на делах Симферопольского окружного суда, который женщины с присущей им коварностью могли ввести в заблуждение). Можно говорить о том, что остальные 68 \% были насильственно умерщвлены.

Говоря о способах детоубийств, можно констатировать тот факт, что в 29,5 \% новорождённые были убиты жестокими способами, они умирали от асфиксии, от ран, от того, что мать оторвала голову. Самой жестокой преступницей в этом случае оказалась двадцатилетняя служанка, которая в послеродовом шоке оторвала или отрезала тупым ножом голову ребенку. Девушка признала себя виновной, однако не помнила, «как все произошло» ${ }^{16}$. Кстати, девушку подвергли аресту при полиции на семь дней, и на нее были возложены судебные издержки ${ }^{17}$. Другая обвиняемая, магометанка 20 лет, не признавала себя виновной в том, что перерезала горло ребенку, который был обнаружен около ее деревни ${ }^{18}$. Она отрицала сам факт беременности, несмотря на то, что медицинский осмотр при двух понятых постановил, что роды были. Одна из понятых, мать 15 детей, утверждала, что «по груди можно все определить, а у обвиняемой «грудь была полна, а соски черные» ${ }^{19}$. Подсудимая находилась в лихорадочном состоянии, дрожала, нервничала, говорила, что «беременной не могли видеть, так как таковой не являлась» ${ }^{20}$. Остальные прибегали к менее кровавым способам, душив ребенка, причем, по их утверждениям, детки рождались мертвыми ${ }^{21}$.

Отдельно следует осветить необычный случай в Симферопольском уезде; прежде всего случай интересен тем, что девушка «отправилась в отхожее место для отправления естественных надобностей, она там и разрешилась от бремени, но сначала этого не заметила и поняла, что это произошло, лишь придя к себе в комнату и заметив на своем белье кровь» ${ }^{22}$. Звучит такое неправдоподобно, однако Э.Р. Гофман объяснил такие случаи в своем исследовании. Опыт показывал, что большинство случаев родов с падением прихо-

${ }^{16}$ ГАРК Ф. 376. Оп. 6. Д. 819. Л. 2-3. Дело о крестьянке Прасковье Васильевой Тищенко, обвиняемой по 2 ч. 1460. Вступило дело 19 ноября 1907 г.

${ }^{17}$ Там же. Л. 38.

${ }^{18}$ ГАРК Ф. 376. Оп. 6. Д. 355. Л. 4. О крестьянке Мархубе.

${ }^{19}$ Там же. Л. 92.

${ }^{20}$ Там же. Л. 89-90.

${ }^{21}$ ГАРК Ф. 376. Оп. 2. Д. 336. Л. 2. О мещанке; Д. 532. Л. 2. Асфиксия; Д. 860. Л. 3. В соломенной ограде двора был обнаружен труп младенца женского пола; Ф. 376. Оп. 6. Д. 541. Л. 3. Утопление в туалете.

${ }^{22}$ ГАРК Ф. 376. Оп. 6. Д. 335. Л. 2. В отхожем месте труп новорожденного младенца. 
дится на долю первородящих, потому что они по неопытности не умели оценивать своего положения и не замечали наступления родов. Первые боли, по словам Э.Р. Гофмана, принимались первородящими за кишечные колики, это побуждало их отправиться в отхожее место, где их и настигали роды [Гофман, 1887, с. 601]. Пуповина, натягиваясь, могла увлечь за собой послед [Гофман, 1887, с. 602]. Таким образом, теоретически девушка могла говорить правду. По словам девушки, «роды случились так быстро, что я их и не заметила» ${ }^{23}$. Существовала гипотеза, что тайные роженицы разрешаются скорее других. Объяснялось тем, что психическое возбуждение вызывает «стремительное опорожнение матки» и тетаническое ее сокращение [Гофман, 1887, с. 613-614].

В остальных 9,5\% случаев точную причину смерти найденных тел новорождённых детей установить не удалось. Приходилось опираться лишь на «честные слова матерей», которые, по оценкам судебно-медицинской экспертизы, в большинстве случаев находились в послеродовом состоянии и были подвержены истерии. Показания женщин часто были запутанными и не соответствовали по факту первым допросам. К примеру, женщина, на которую анонимно донесли городовому, сообщила, что оповестила двух своих сожителей (мужчин), что ребенок родился мертвым, и она бросила трупик в Днепр. Немного позднее девушка дала показания о том, что сделала это по настоянию своего сожителя, с кем прижила ребенка вне брака. Спустя время обвинила его в том, что мужчина давал во время беременности «что-то пить, от чего у нее из половых органов шла обильно кровь» ${ }^{24}$. В итоге девушку подвергли аресту при полиции на пять дней и возложили на нее судебные издержки, мужчину ожидала неделя заключения ${ }^{25}$. Также можно привести другой случай, когда слова матери нельзя проверить, так как «закопала ребенка на чьём-то огороде, место указать не смогла, ребенка найти не удалось» ${ }^{26}$. По словам девушки, она «ничего не помнила, была в беспамятстве» ${ }^{27}$. Девушку не осудили, она числилась как замужняя, однако муж пропал на фронтах Первой мировой войны. В военное и послевоенное время наказание таких матерей было не строгим, так как «все всё понимали». Как пример, дело за 1918 г. содержало мало документов, так как денег на судебно-медицинскую экспертизу не было, да и с матери вряд ли смогли бы взыскать средства за судебные издержки ${ }^{28}$.

Матерей вызывали в суд, взваливая на них судебные издержки и порицая их за неблаговидные поступки. В судах многие признавали себя виновными, беря на себя ответственность за содеянное. В подавляющем большинстве случаев «волнуемые стыдом и страхом» покидали скамью подсудимых сразу же после завершения суда.

\section{Заключение}

Подводя итог, важно указать на оценку инфантицида дореволюционными исследователями, которые перекладывали груз ответственности за рассматриваемое злодеяние на плечи общества, которое как бы выталкивало девушку с незаконнорожденным ребенком на руках из общественной жизни. Лишенная возможности заработать на жизнь себе и ребенку, девушка прибегала к крайним мерам - инфантициду. Большая часть детоубийц, терзая себя мыслями об их печальной с ребенком участи всю беременность, впадая в крайнюю степень отчаяния, избавлялась от ребенка в первые часы после родоразрешения. Практически все преступницы, которых обличали, найдя спрятанное тело их ребенка, рассказывали о том, что ребенок был мертворожденный. Однако медицинская экспертиза установила малый процент мертворожденных детей - 12 \%, немногим более погибали от не предоставления помощи - $20 \%$. Все остальные новорожденные дети матерей, которые

\footnotetext{
${ }^{23}$ Там же. Л. 60.

${ }^{24}$ ГАРК Ф. 376. Оп. 6. Д. 389. Л. 2-3.

${ }^{25}$ ГАРК Ф. 376. Оп. 6. Д. 389. Л. 28. О крестьянке Елене Степановой Кучв. Нач. 20 ноября 1904 г.

${ }^{26}$ ГАРК Ф. 483. Оп. 2. Д. 21. Л. 22. Дело об обвиняемой в сокрытии трупа рожденного ребенка.

${ }^{27}$ Там же. Л. 50.

${ }^{28}$ ГАРК Ф. 483. Оп. 2. Д. 63. Л. 12. Начато за 1918 г. 25 июля.
} 
божились, что их дети родились мертвыми, были убиты. Причем половина детей были умерщвлены с крайней жестокостью: им отрывали головы, били ребенка головой об камки, держа за ножки, кидали в ретирадное место, предварительно забив камнями. Остальные случаи причислялись к менее жестоким, однако все равно это было насильственное умерщвление ребенка. Говоря о наказании преступниц, следует указать на тот факт, что таких женщин привлекали не по статье детоубийство, так как все женщины, сидя на скамье подсудимых, раскаивались в содеянном, будучи «волнуемыми стыдом и страхом». Их могли привлечь за сокрытие трупа и оставлении без помощи. Однако, анализируя наказания за исследуемое злодеяние, можно сказать, что женщин, привлеченных к ответственности на территории Таврической губернии в середине XIX - начале XX в., практически не было. В основном женщины выплачивали судебные издержки, исчисляемые в паре рублей, и вновь вливались в размеренную жизнь губернии.

\section{Благодарности}

Автор выражает глубокую благодарность научному руководителю, кандидату исторических наук Алле Анатольевне Задерейчук.

\section{Список литературы}

1. Бабичев А. Г. Историческое становление российского уголовного законодательства об убийстве матерью новорожденного ребенка. URL: https://cyberleninka.ru/article/n/istoricheskoestanovlenie-rossiyskogo-ugolovnogo-zakonodatelstva-ob-ubiystve-materyu-novorozhdennogo-rebenka (дата обращения: 15 апреля 2021).

2. Василевский Л.М. 1927. Аборт как социальное явление. Днепропетровск, Космос. 162.

3. Гернет М.Н. 1911. Детоубийство. Социологическое и сравнительно-юридическое исследование: с приложением 12 диаграмм. Москва, Типография Императорского Московского Университета, 318.

4. Глебовский С. 1904. Детоубийство в Лифляндской губернии. Вестник общественной гигиены, судебной и криминологической медицины. 9-10: 46-47.

5. Глебовский С. Детоубийство в Лифляндской губернии. 1912. [Б. м.]: [б. и.]. 55.

6. Гофман Э.Р. 1887. Учебник судебной медицины. Санкт-Петербург: тип. Деп. уделов, 762.

7. Громов С. 1838. Краткое изложение судебной медицины для академического и практического употребления. Санкт-Петербург: тип. Э. Праца и К은 576.

8. Громов С.А. 1832. Краткое изложение судебной медицины для академического и практического употребления. Санкт-Петербург: В тип. Штаба Отдельного Корпуса Внутренней Стражи, 554.

9. Жеребчиков Д.П. Оставление ребенка и детоубийство в Российской провинции: историко-правовые аспекты (на примере губерний Центрального Черноземья второй половины XIX - начала XX вв.). URL: https://cyberleninka.ru/article/n/ostavlenie-rebenka-i-detoubiystvo-vrossiyskoy-provintsii-istoriko-pravovye-aspekty-na-primere-guberniy-tsentralnogo-chernozemya-vtoroy (дата обращения: 14 апреля 2021).

10. Змиев Б.Н. 1927. Детоубийство. Право и Жизнь. Москва, Книга 6-7: 89-96.

11. Линденберг В.Г. Материалы к вопросу о детоубийстве и плодоизгнании в Витебской губернии: (по данным Витеб. окр. суда за десять лет, 1897-1906): дис. д-ра мед. Юрьев: тип. К. Маттисена, 1910, 84 с.

12. Михель Д.В. Общество перед проблемой инфантицида: история, теория, политика. URL: https://cyberleninka.ru/article/n/obschestvo-pered-problemoy-infantitsida-istoriya-teoriya-politika (дата обращения: 15 апреля 2021).

13. Мицюк Н.А., Пушкарева Н.Л. «Плодоизгнание» как основной способ контроля рождаемости у крестьянок XIX в. URL: https://cyberleninka.ru/article/n/plodoizgnanie-kak-osnovnoysposob-kontrolya-rozhdaemosti-u-krestyanok-xix-v (дата обращения: 15 апреля 2021).

14. Несколько случаев детоубийства. 1862. Журнал Министерства Юстиции. СПб., 202.

15. Общество русских врачей в память Н.И. Пирогова. Съезд (1913; 12; Петербург). Двенадцатый Пироговский съезд. Петербург, 29 мая - 5 июня 1913 г. Санкт-Петербург, 1913, Вып. 2. 512. 
16. Орлов А.Н. 1868. О покушении на преступление по началам науки и современным законодательствам. Москва, Унив. тип. Катков и Кํ, 161.

17. Охорович Ю. 1876. Любовь, преступление и нравственность: Несколько задач из области «уголовной психологии». Минск, тип. Б.И. Соломонова, 169.

18. Салгир. 1898. 26 октября. 131: 2.

19. Салгир. 1898. 27 ноября. 159: 3.

20. Таганцев Н.С. 1871. О преступлениях против жизни по русскому праву. Том II. СанктПетербург, Типография А.М. Котомина, 524.

21. Шашков С.С. 1871. Исторические судьбы женщины, детоубийство и проституция. Санкт-Петербург, Н.А. Шигин, 623.

22. Шашков С.С. 1898. Исторические судьбы женщины: детоубийство и проституция. Очерк истории русской женщины. СПб., 606.

23. Шевченко А.B. Классификация детоубийств. URL: https://cyberleninka.ru/article/n/klassifikatsiya-detoubiystv (дата обращения: 14 апреля 2021).

24. Юкина И.И. Дискуссия об абортах в Российской империи: частная жизнь и новая идентичность. URL: https://cyberleninka.ru/article/n/diskussiya-ob-aborah-v-rossiyskoy-imperiichastnaya-zhizn-i-novaya-identichnost (дата обращения: 15 апреля 2021).

\section{References}

1. Babichev A.G. Istoricheskoe stanovlenie rossiyskogo ugolovnogo zakonodatel'stva ob ubiystve mater'yu novorozhdennogo rebenka [Historical formation of the Russian criminal legislation on the murder of a newborn child by a mother]. URL: https://cyberleninka.ru/article/n/istoricheskoestanovlenie-rossiyskogo-ugolovnogo-zakonodatelstva-ob-ubiystve-materyu-novorozhdennogo-rebenka (data obrashcheniya: 15 aprelya 2021).

2. Vasilevskiy L.M. 1927. Abort kak sotsial'noe yavlenie [Abortion as a social phenomenon]. Dnepropetrovsk, Kosmos. 162.

3. Gernet M.N. 1911. Detoubiystvo. Sotsiologicheskoe i sravnitel'no-yuridicheskoe issledovanie: s prilozheniem 12 diagramm [Infanticide. Sociological and comparative legal research: with an appendix of 12 diagrams]. Moscow, Tipografiya Imperatorskogo Moskovskogo Universiteta, 318.

4. Glebovskiy S. 1904. Detoubiystvo v Liflyandskoy gubernii [Infanticide in the Livonia province]. Vestnik obshchestvennoy gigieny, sudebnoy i kriminologicheskoy meditsiny. 9-10: 46-47.

5. Glebovskiy S. 1912. Detoubiystvo v Liflyandskoy gubernii [Infanticide in the Livonia province]. [B. m.]: [b. i.]. 55.

6. Gofman E.R. 1887. Uchebnik sudebnoy meditsiny [Textbook of forensic medicine.]. St. Petersburg: tip. Dep. udelov, 762.

7. Gromov S. 1838. Kratkoe izlozhenie sudebnoy meditsiny dlya akademicheskogo i prakticheskogo upotrebleniya [Summary of forensic medicine for academic and practical use.]. St. Petersburg: tip. E. Pratsa i K ${ }^{\circ}, 576$.

8. Gromov S.A. 1832. Kratkoe izlozhenie sudebnoy meditsiny, dlya akademicheskogo i prakticheskogo upotrebleniya [Summary of forensic medicine, for academic and practical use]. St. Petersburg: V tip. Shtaba Otdel'nogo Korpusa Vnutrenney Strazhi, 554.

9. Zherebchikov D.P. Ostavlenie rebenka i detoubiystvo v Rossiyskoy provintsii: istorikopravovye aspekty (na primere guberniy Tsentral'nogo Chernozem'ya vtoroy poloviny XIX - nachala $\mathrm{XX}$ vv.) [Abandonment of a child and infanticide in the Russian Province: historical and legal aspects (on the example of the provinces of the Central Chernozem Region of the second half of the XIX - early XX centuries]. URL: https://cyberleninka.ru/article/n/ostavlenie-rebenka-i-detoubiystvo-v-rossiyskoyprovintsii-istoriko-pravovye-aspekty-na-primere-guberniy-tsentralnogo-chernozemya-vtoroy (data obrashcheniya: 14 aprelya 2021).

10. Zmiev B.N. 1927. Detoubiystvo. Pravo i Zhizn' [Infanticide. Law and Life]. Moscow, Kniga 6-7: 89-96.

11. Lindenberg V.G. Materialy k voprosu o detoubiystve i plodoizgnanii v Vitebskoy gubernii: (po dannym Viteb. okr. suda za desyat' let, 1897-1906) [Materials on the issue of infanticide and plodoizgnanii in the Vitebsk province: (according to the data of the Vitebsk Regional Court for ten years, 1897-1906)]: dis. d-ra med. Yur'ev: tip. K. Mattisena, 1910, 84 s.

12. Mikhel' D.V. Obshchestvo pered problemoy infantitsida: istoriya, teoriya, politika [Society before the problem of infanticide: history, theory, politics.]. URL: 
https://cyberleninka.ru/article/n/obschestvo-pered-problemoy-infantitsida-istoriya-teoriya-politika (data obrashcheniya: 15 aprelya 2021).

13. Mitsyuk N.A. Pushkareva N.L. «Plodoizgnanie» kak osnovnoy sposob kontrolya rozhdaemosti u krest'yanok XIX v. [«Infanticide» as the main method of birth control in peasant women of the XIX century] URL: https://cyberleninka.ru/article/n/plodoizgnanie-kak-osnovnoy-sposobkontrolya-rozhdaemosti-u-krestyanok-xix-v (data obrashcheniya: 15 aprelya 2021).

14. Neskol'ko sluchaev detoubiystva [Several cases of infanticide.] 1862. Zhurnal Ministerstva Yustitsii. SPb., 202.

15. Obshchestvo russkikh vrachey v pamyat' N.I. Pirogova. S"ezd [Society of Russian Doctors in memory of N.I. Pirogov. Congress] (1913; 12; Peterburg). Dvenadtsatyy Pirogovskiy s"ezd. Peterburg, 29 maya - 5 iyunya 1913 g. St. Petersburg, 1913, Vyp. 2. 512.

16. Orlov A.N. 1868. O pokushenii na prestuplenie po nachalam nauki i sovremennym zakonodatel'stvam [On the attempted crime according to the principles of science and modern legislation]. Moscow, Univ. tip. Katkov i Ko 161.

17. Okhorovich Yu. 1876. Lyubov', prestuplenie i nravstvennost': Neskol'ko zadach iz oblasti «ugolovnoy psikhologii» [Love, crime and morality: Several problems from the field of «criminal psychology»]. Minsk, tip. B.I. Solomonova, 169.

18. Salgir [Salgir]. 1898. 26 oktyabrya. 131: 2.

19. Salgir [Salgir]. 1898. 27 noyabrya. 159: 3.

20. Tagantsev N.S. 1871. O prestupleniyakh protiv zhizni po russkomu pravu [On crimes against life under Russian law]. Tom II. St. Petersburg, Tipografiya A.M. Kotomina, 524.

21. Shashkov S.S. 1871. Istoricheskie sud'by zhenshchiny, detoubiystvo i prostitutsiya [The historical fate of women, infanticide and prostitution]. St. Petersburg, N.A. Shigin, 623.

22. Shashkov S.S. 1898. Istoricheskie sud'by zhenshchiny: detoubiystvo i prostitutsiya. Ocherk istorii russkoy zhenshchiny [The historical fate of women: infanticide and prostitution. Essay on the history of Russian women]. SPb., 606.

23. Shevchenko A.V. Klassifikatsiya detoubiystv [Classification of infanticide]. URL: https://cyberleninka.ru/article/n/klassifikatsiya-detoubiystv (data obrashcheniya: 14 aprelya 2021).

24. Yukina I.I. Diskussiya ob abortakh v Rossiyskoy Imperii: chastnaya zhizn' i novaya identichnost' [Discussion about abortions in the Russian Empire: private life and new identity]. URL: https://cyberleninka.ru/article/n/diskussiya-ob-aborah-v-rossiyskoy-imperii-chastnaya-zhizn-i-novayaidentichnost (data obrashcheniya: 15 aprelya 2021).

\section{ИНФОРМАЦИЯ ОБ АВТОРЕ}

Масленникова Валерия Андреевна, аспирант кафедры истории России Таврической академии Крымского федерального университета имени В.И. Вернадского, г. Симферополь, Россия

\section{INFORMATION ABOUT THE AUTHOR}

Maslennikova Valeria Andreevna, postgraduate student of the Department of Russian History of the Taurida Academy of the Crimean Federal University named after V.I. Vernadsky, Simferopol, Russia 